\title{
Long-term gliclazide treatment improves the in vitro glucose-induced insulin release in rats with Type 2 (non-insulin-dependent) diabetes induced by neonatal streptozotocin*
}

\author{
P.Serradas, D. Bailbé and B. Portha \\ Laboratoire Physiologie du Développement, CNRS UA 307, Université Paris 7, Paris, France
}

\begin{abstract}
Summary. Neonatal rats treated with streptozotocin on the day of birth (n0-STZ) or on day 5 (n5-STZ) exhibited when fully grown a very mild or frank basal hyperglycaemia respectively and a specific failure of insulin release in response to glucose. To determine whether short (1 day) or long-term (30 days) gliclazide treatment modifies the pancreatic insulin content and the B-cell response to secretagogues, diabetic rats were given oral gliclazide ( $10 \mathrm{mg} / \mathrm{kg}$ per day) and compared to control diabetic and non-diabetic rats. Insulin secretion in the isolated perfused pancreas was studied the day after the last gliclazide administration. In severely hyperglycaemic n5STZ rats (plasma glucose levels $>16 \mathrm{mmol} / \mathrm{l}$ ) long-term gliclazide treatment did not lower the plasma glucose values, did not affect the pancreatic insulin stores, nor did it significantly modify the insulin release in vitro in response to glucose or arginine. In moderately hyperglycaemic n5-STZ rats (plasma glucose levels $<16 \mathrm{mmol} / \mathrm{l}$ ) the plasma glucose levels declined progressively reaching $8 \mathrm{mmol} / \mathrm{l}$ as a mean at the end of the gliclazide therapy. In the n5-STZ rats responsive to gliclazide the pancreatic insulin stores were increased twofold as compared to values in untreated n5-STZ rats, however, this difference did not reached significance and the pancreatic in-
\end{abstract}

sulin stores in the responsive gliclazide treated rats remained depleted by $76 \%$ compared to normal insulin stores. In the n0-STZ rats (very mild hyperglycaemia) the long-term gliclazide treatment did not significantly modify the plasma glucose levels or the pancreatic insulin stores. After the 30-day gliclazide therapy in both the n5-STZ gliclazide responder group and the n0-STZ group: (1) the in vitro glucose-induced insulin secretion was increased three to fivefold, (2) the response to arginine which was basically increased in the untreated diabetic rats was again amplified two to threefold, (3) the insulin release in response to gliclazide was unchanged. In conclusion, long-term gliclazide therapy augments stimulated insulin secretion in these two rat models of Type 2 (non-insulin-dependent) diabetes and does not induce any refractoriness to acute sulfonylurea stimulation. The improvement of Bcell function observed here was not related to the concomitant variations of hyperglycaemia and/or pancreatic insulin content

Key words: Type 2 (non-insulin-dependent) diabetes, gliclazide therapy, insulin release, insulin content, B-cell desensitization to glucose
Although sulfonylureas are widely used in the treatment of Type 2 (non-insulin-dependent) diabetes the mechanism of their hypoglycaemic action remains unclear. It has been demonstrated that short-term administration of sulfonylureas stimulates insulin secretion in normal animals [1], in normal subjects and in patients with Type 2 diabetes [2-4]. However, contradictory data exist on the effect of long-term sulfonylurea administration on B-cell function [5-13]. Several studies in humans with Type 2 diabetes have failed to show any increase in basal or stimulated insulin levels

\footnotetext{
* This work was presented in part at the 24th Annual Meeting of the European Association of the Study of Diabetes, Paris, France, 5-8 September 1988
}

after long-term sulfonylurea treatment [5-7, 14]. These studies have not taken into account the possibility that, because of the sulfonylurea-induced fall in blood glucose, the effect of the drug in enhancing islet function would not result in long-term increased insulin levels, but rather would maintain similar pretreatment insulin levels with lower hyperglycaemia. Using protocols designed to test such a possibility, it has been found that long-term sulfonylurea therapy indeed increases glucose-induced insulin secretion and the suggestion was made that long-term sulfonylurea administration to patients with Type 2 diabetes improves their impaired Bcell sensitivity to glucose $[15,16]$.

The availability of neonatal streptozotocin (n-STZ) rat models of Type 2 diabetes provided an opportunity 
Table 1. Characteristics of the diabetic rats (n5-STZ and n0-STZ models) before (day 0) or at the end (day 30) of gliclazide treatment $\left(10 \mathrm{mg} \cdot \mathrm{Kg}^{-1} \cdot\right.$ day $\left.^{-1}\right)$. On the basis of plasma glucose values before the gliclazide therapy, among the n5-STZ diabetic rats, two groups have been descriminated, a group with severe hyperglycaemia $(>16 \mathrm{mmol} / 1)$ (group A) and a group with moderate hyperglycaemia $(<16 \mathrm{mmol} / 1)($ group B)

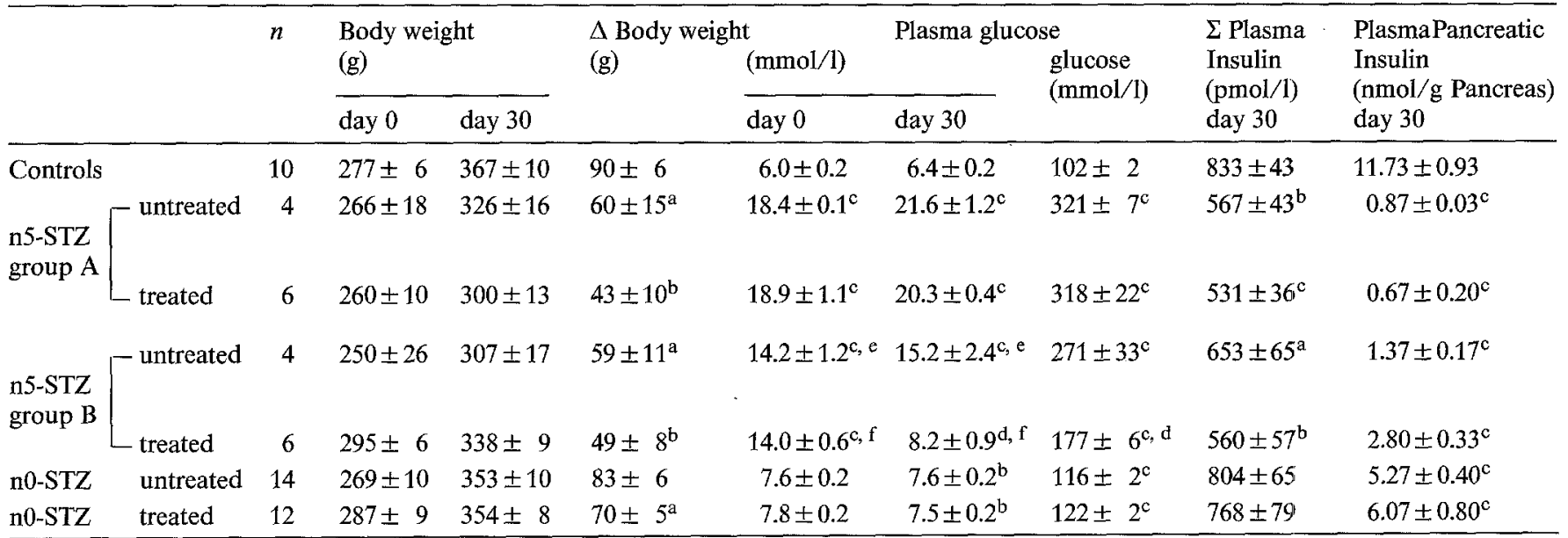

$\Sigma$ plasma glucose in the sum of basal plasma glucose values every other day during the 30-day gliclazide treatment.

$\Delta$ body weight is the weight gain during the 30-day gliclazide therapy.

Values are means \pm SEM; $n=$ number of animals in each group.

${ }^{\mathrm{a}}=p<0.05 ;{ }^{\mathrm{b}}=p<0.01$ and $^{\mathrm{c}}=p<0.001$ vs controls, ${ }^{\mathrm{d}}=p<0.01$ vs untreated corresponding group, ${ }^{\mathrm{e}}=p<0.02$ and ${ }^{\mathrm{f}}=p<0.001$ vs group A corresponding group

to study the influence of long-term sulfonylurea administration on B-cell function. These diabetic rats exhibited a specific failure of insulin release in response to glucose coexisting with a relative preservation of the responses to other secretagogues [17]. Such a pattern resembles that shown in some studies of human Type 2 diabetes [18-20] and is also charcteristic of Type 1 diabetes in the early stage of the disease [21] and of Type 2 diabetes of the young [22].

This study was designed to determine if short-term (1 day) or long-term ( 30 days) oral gliclazide treatment modifies the pancreatic insulin content and the in vitro B-cell response to secretagogues (glucose, arginine and gliclazide) using the isolated perfused pancreas technique. Two different versions of the neonatal streptozotocin rat model were used: the n5-STZ model (streptozotocin administration on day 5 after birth) exhibiting frank basal hyperglycaemia, strong reduction of pancreatic insulin stores and insulin resistance [23] and the n0-STZ model (streptozotocin administration on the day of birth) with very mild basal hyperglycaemia, half reduced pancreatic insulin stores and no insulin resistance [24].

\section{Materials and methods}

\section{Animals}

Albino Wistar rats bred in our colony were fed ad libitum with a commercial pelleted chow (Usine Alimentation Rationnelle, ref. 113, Villemoisson-sur-Orge, France).

Insulin deficiency was induced in the neonates by administration of streptozotocin (STZ, i.p. injection) diluted in $30 \mu \mathrm{l}$ of citrate buffer $(0.05 \mathrm{~mol} / 1, \mathrm{pH} 4.5)$. Two groups of male neonates were raised: one received STZ $(100 \mu \mathrm{g} / \mathrm{g})$ on day of birth (n0-STZ rats) and the other received STZ $(80 \mu \mathrm{g} / \mathrm{g})$ five days after birth (n5-STZ rats). All the animals (STZ and control rats) were weaned 28 days after birth.

After STZ injection, a high death rate was detected only in the n5STZ group ( $50 \%$ of the neonates as a mean) in the three days following STZ injection, the 5 -STZ litters were then redistributed to reach a number of rats similar ( 8 to 10 ) to that in the other (diabetic and control) groups. All the surviving animals were kept. Spontaneous evolution of the neonatal diabetes led to Type 2 diabetes in the adults [23].

\section{Sulfonylurea therapy}

At 2 months of age the diabetic rats were given an aqueous solution of gliclazide (Servier, Gidy, France) orally (using a gastric tube) in one daily dose (10 $\mathrm{mg} / \mathrm{kg}$ body weight) for 1 day (short-term treatment) or 30 days (long-term teatment). The drug dosage was adjusted according to the weight of the animals at 09.30 hours daily. Diabetic and non diabetic rats receiving the placebo (water) only for 30 days were used as the untreated diabetic group and control group respectively.

Blood for plasma glucose and insulin measurements was obtained by tail snipping at 09.30 hours, before gliclazide administration every other day throughout therapy. This was done in both the treated and the untreated diabetic rats and the control rats.

The pancreas was removed $24 \mathrm{~h}$ after the final dose of drug, and insulin secretion was studied using the in vitro isolated perfused pancreas technique.

\section{Isolated pancreas perfusion technique}

The animals were anaesthetised with pentobarbital sodium $(4 \mathrm{mg} / 100 \mathrm{~g}$ body weight, i.p.). Isolation and perfusion of the pancreas was performed as previously described [17]. The perfusate was a Krebs-Ringer bicarbonate buffer with the following components: $118 \mathrm{mmol} / 1 \mathrm{NaCl}, 4 \mathrm{mmol} / 1 \mathrm{KCl}, 2.5 \mathrm{mmol} / 1 \mathrm{CaCl}_{2}, 1.2 \mathrm{mmol} / \mathrm{l}$ $\mathrm{MgSO}_{4}, 1.2 \mathrm{mmol} / 1 \mathrm{KH}_{2} \mathrm{PO}_{4}, 25 \mathrm{mmol} / 1 \mathrm{NaHCO}_{3}, 1.25 \mathrm{~g} / 1$ fatty acid-free bovine serum albumin (Sigma, St Louis, Mo, USA) and $40 \mathrm{~g} / 1$ dextran T 70 (Pharmacia, Uppsalla, Sweden). D-glucose (Merck, Darmstadt, FRG), L-arginine (Sigma), or gliclazide (Servier) 
were succesively administered through a sidearm syringe as required. The complete effluent ( $3 \mathrm{ml} / \mathrm{min}$ ) was collected from a cannula in the portal vein at $1 \mathrm{~min}$ intervals in chilled tubes and stored at $-20^{\circ} \mathrm{C}$ until assay. Following perfusion, the pancreas was weighed, homogenized and centrifuged at $4^{\circ} \mathrm{C}$ in an acid alcohol solution (75\% ethanol, $1.5 \%$ $\mathrm{HCl} 12 \mathrm{mmol} / 1,23.5 \%$ distilled water). The supernant was stored at $-20^{\circ} \mathrm{C}$ until assay.

\section{Analytical techniques and calculations}

Plasma glucose was determined with a glucose analyser (Beckman, Fullerton, Calif, USA). Immunoreactive insulin in the perfusate and pancreata was estimated with purified rat insulin as standard (Novo, Copenhagen, Denmark), antibodies to mixed (porcine and bovine) insulin and porcine ${ }^{125} \mathrm{I}$ monoiodinated insulin [25]. Charcoal was used to separate free from bound hormone. This method allows the determination of $6 \mu \mathrm{U} / \mathrm{ml}(0.25 \mathrm{ng} / \mathrm{ml})$, with an inter- and intra-assay coefficient of variation of $10 \%$.

Integrated basal plasma glucose level was expressed as the sum of basal plasma glucose values every other day during the 30 day gliclazide therapy ( $\Sigma$ plasma glucose). Insulin secretion rate per total pancreas was calculated by multiplying the insulin concentration in the samples by the flow rate and was expressed as $\mu \mathrm{U} / \mathrm{min}$. Total insulin response to glucose, arginine or gliclazide was obtained by planimetry of the individual perfusion profiles and expressed as the difference in hormonal secretion rate $(\mu \mathrm{U}$ insulin $/ \mathrm{min}$ ) relative to the mean hor monal output recorded at the end of the pre-stimulation period. Results are given as means \pm SEM.

\section{Statistical analysis}

Statistical analysis was performed using analysis of variance ANOVA (Scheefe-f-test).

\section{Results}

\section{Characteristics of the $n 5-S T Z$ and $n 0-S T Z$ diabetic rats after the 30-day gliclazide treatment}

Gliclazide treatment in the $n 5-S T Z$ rats (Table 1). Among the adult male n5-STZ diabetic rats, two populations can be easily selected on the basis of the basal plasma glucose value as measured in the non-fasted state. In 10 of $20 \mathrm{n5-STZ}$ rats (group A) plasma glucose levels measured before placebo or drug administration were above $16 \mathrm{mmol} / 1$ (pre-treatment value: $18.7 \pm 0.7 \mathrm{mmol} / \mathrm{l}$ ) while in the remaining $10 \mathrm{n} 5-\mathrm{STZ}$ rats (group B) it was below $16 \mathrm{mmol} / 1$ (pre-treatment value: $14.1 \pm 0.6 \mathrm{mmol} / \mathrm{l}$ ). Basal pre-treatment plasma insulin levels were significantly impaired $(p<0.05)$ in both groups of diabetic rats as compared to normal values (data not shown). Mean pancreatic insulin content as estimated in the 30-day placebo rats was significantly reduced in both diabetic groups (by $93 \%$ in group $\mathrm{A}$ and $88 \%$ in group $\mathrm{B}, p<0.001$ ) compared to normal insulin stores.

The 30-day gliclazide treatment did not affect growth of the animals because weight gain in both groups of treated diabetic rats during this period $(43 \pm 10 \mathrm{~g}, n=6$ in group A, $49 \pm 8 \mathrm{~g}, n=6$ in group B)

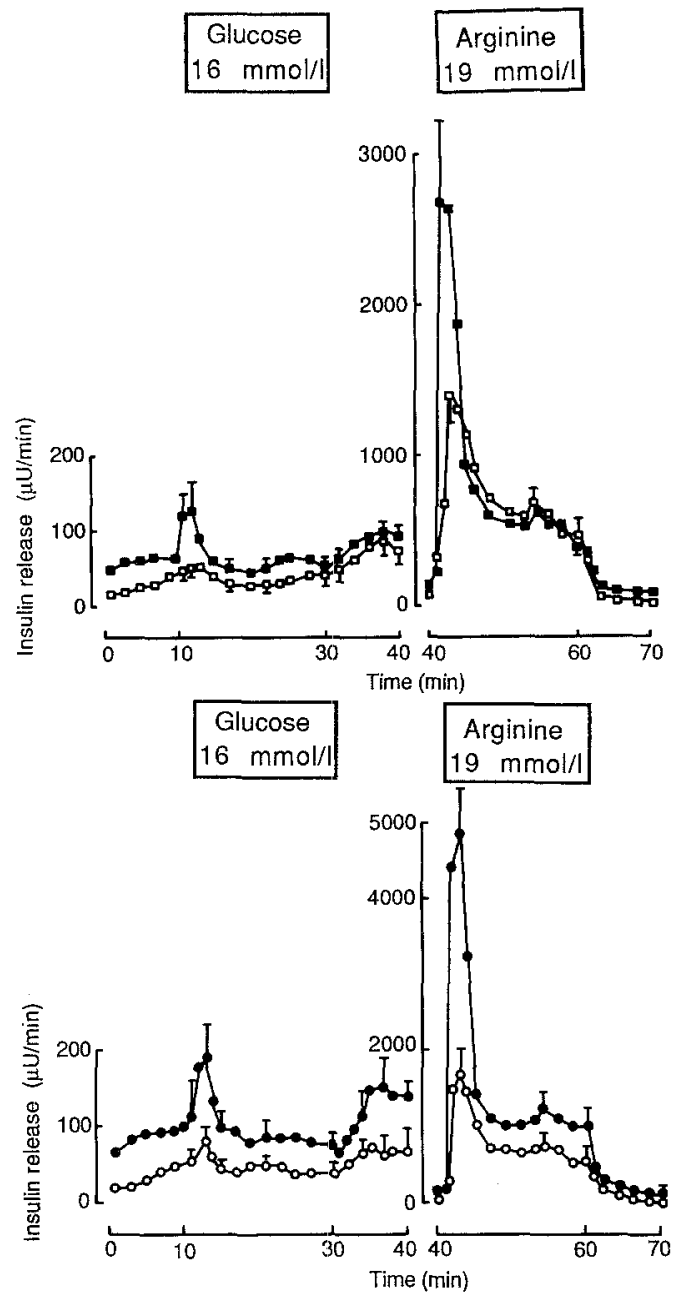

Fig. 1. Effect of $16 \mathrm{mmol} / 1$ glucose and $19 \mathrm{mmol} / 1$ arginine on insulin release from perfused pancreas of untreated $\mathrm{n} 5 \mathrm{-STZ}$ diabetic rats with basal plasma glucose values above $16 \mathrm{mmol} / 1$ (group A) ( $\square$ ), untreated n5-STZ diabetic rats with basal plasma glucose values below $16 \mathrm{mmol} / 1$ (group B) (O), 30-day gliclazide treated $\mathrm{n} 5$-STZ rats which revealed non-responders to gliclazide (group A) ( $\boldsymbol{\square}$ ) and 30-day gliclazide treated $\mathbf{n} 5-\mathrm{STZ}$ rats which revealed responders to gliclazide (group B) (O). Experiments were carried out in the absence of glucose during pre- and post-stimulatory periods. Each point represents the mean \pm SEM of 4-6 observations in each group

was similar to that in the related group of untreated diabetic rats $(60 \pm 15 \mathrm{~g}, n=4$ in group A, $59 \pm 11 \mathrm{~g}, n=4$ in group B) and remained significantly lower $(p<0.05)$ than that of the non-diabetic control rats $(90 \pm 6 \mathrm{~g}$, $n=10$ ). In the group A gliclazide treated $\mathrm{n} 5$-STZ rats, the treatment was without significant effect upon the basal plasma glucose level which remained high, as indicated by the value of $\Sigma$ plasma glucose which is similar to that in the related group A untreated rats. At variance in the group B gliclazide treated $\mathrm{n} 5-\mathrm{STZ}$ rats the basal plasma glucose levels progressively declined reaching $8.2 \pm 0.9 \mathrm{mmol} / 1$ at the end of treatment and the value of $\Sigma$ plasma was significantly lower $(p<0.01)$ than that of the untreated diabetic rats but was still significantly higher $(p<0.001)$ compared to the nondiabetic rats. Thus, among the 12 gliclazide treated n5- 

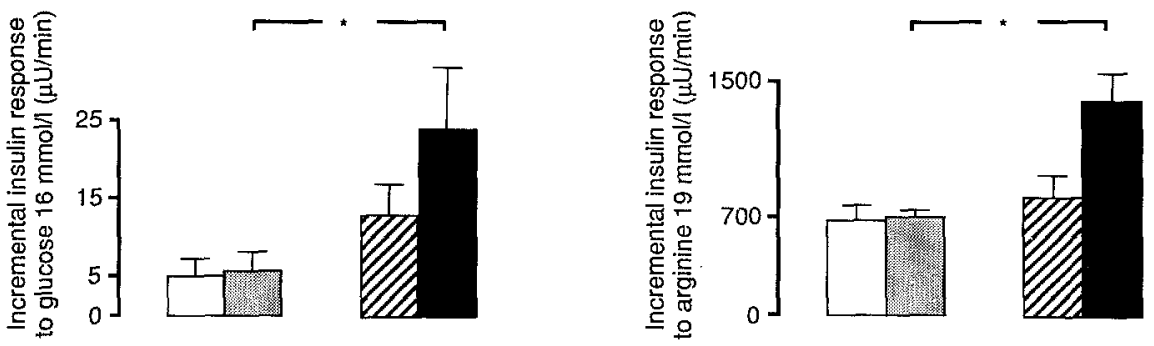

Fig. 2. Incremental insulin response to $16 \mathrm{mmol} / 1$ glucose and $19 \mathrm{mmol} / \mathrm{l}$ arginine above basal release in untreated $\mathrm{n} 5-\mathrm{STZ}$ diabetic rats with basal plasma glucose values above $16 \mathrm{mmol} / 1$ (group A) (口), untreated n5-STZ diabetic rats with basal plasma glucose value below $16 \mathrm{mmol} / \mathrm{l}$ (group B) (䫾), 30-day gliclazide treated n5-STZ rats which revealed non-responders to gliclazide (group A) (因) and 30day gliclazide treated n5-STZ rats which revealed responders to gliclazide (group B) ( $\boldsymbol{G}$ ). Values are mean \pm SEM of 4-6 observations in each group. ${ }^{*} p<0.05$

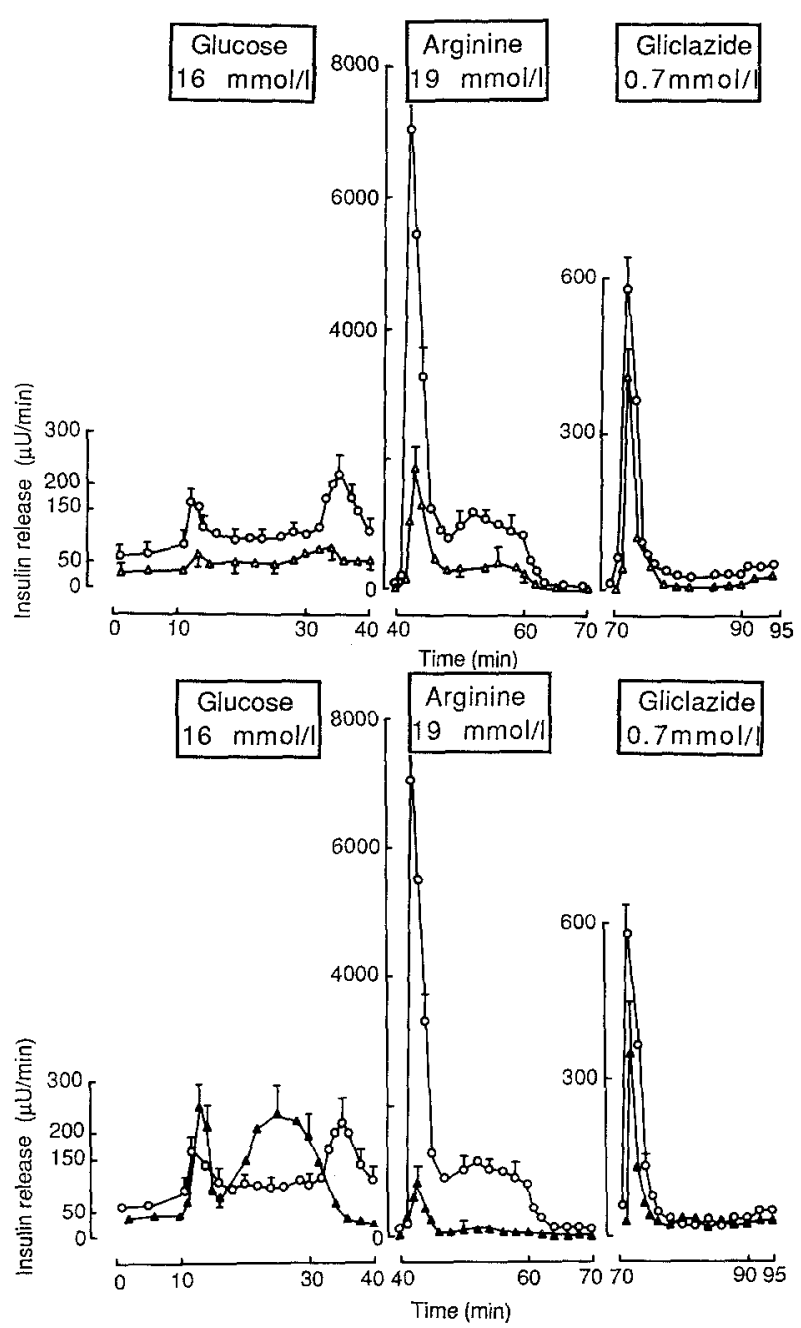

Fig. 3. Effect of $16 \mathrm{mmol} / 1$ glucose, $19 \mathrm{mmol} / 1$ arginine and $0.7 \mathrm{mmol} / 1$ gliclazide on insulin release from perfused pancreases of untreated n0-STZ diabetic rats ( 4 ), n0-STZ diabetic rats that received a 30-day gliclazide therapy (O) (top pannel), and non-diabetic control rats $(\boldsymbol{A})$ and n0-STZ diabetic rats that received a 30-day gliclazide therapy (O) (lower pannel). Experiments were carried out in the absence of glucose during pre- and post-stimulatory periods. Each point represents the mean \pm SEM of 6-9 observations in each group
STZ diabetic rats, two groups can be defined, a non-responder group (corresponding to group A) and a responder group (corresponding to group B). There was no overlap between the two groups. Basal plasma insulin levels remained unaffected by the 30-day gliclazide therapy in both group A and group B rats. At the end of gliclazide therapy the pancreatic insulin stores remained unaffected in group A rats while they increased twofold in group B rats (but the difference did not reach statistical significance). Nevertheless, in this last group they remained largely depleted (by $76 \%$, $p<0.001)$ compared to normal insulin stores.

Gliclazide treatment in the n0-STZ rats (Table 1). Gliclazide treatment did not affect growth of these animals. The treated n0-STZ diabetic rats showed no significant alteration in their basal plasma glucose during treatment as indicated by the $\Sigma$ plasma glucose. At the end of the treatment the plasma glucose value was similar to the corresponding level in the untreated diabetic rats, i. e. they remained slightly hyperglycaemic compared to control rats $(p<0.01)$. Basal plasma insulin levels as compared to non-diabetic control rats were not significantly different in the untreated $\mathrm{n} 0-\mathrm{STZ}$ rats and remained unaffected by sulfonylurea therapy. Mean pancreatic insulin content was reduced (by 55\%, $p<0.001$ ) in the untreated n0-STZ rats and it remained unaffected after the 30-day gliclazide treatment.

In pilot experiments, basal plasma glucose and insulin levels and pancreatic insulin stores were determined in n0-STZ after a 1-day gliclazide treatment: the values did not differ significantly from those in untreated $\mathrm{n} 0-\mathrm{STZ}$ rats (data not shown).

\section{In vitro insulin release by the $n 5-S T Z$ and n0-STZ rats after gliclazide treatment}

Insulin release in the $n 5-S T Z$ rats. When perfusate did not contain glucose, the basal rates of insulin release in the 30-day gliclazide treated diabetic rats $(64 \pm 11 \mu \mathrm{U} / \mathrm{min}$ in group $A, 85 \pm 17 \mu \mathrm{U} / \mathrm{min}$ in group $B$ ) were not significantly different from those in the untreated diabetic animals $(41 \pm 4 \mu \mathrm{U} / \mathrm{min}$ in group $\mathrm{A}, 50 \pm 11 \mu \mathrm{U} / \mathrm{min}$ in group B) but they were significantly higher $(p<0.05)$ compared to the control rats $(18 \pm 1 \mu \mathrm{U} / \mathrm{min}$ ) (Fig. 1). Exposure of the pancreas of the treated diabetic rats (group A and group B) to a glucose concentration $(16 \mathrm{mmol} / \mathrm{l})$ that had induced only a marginal secretory 

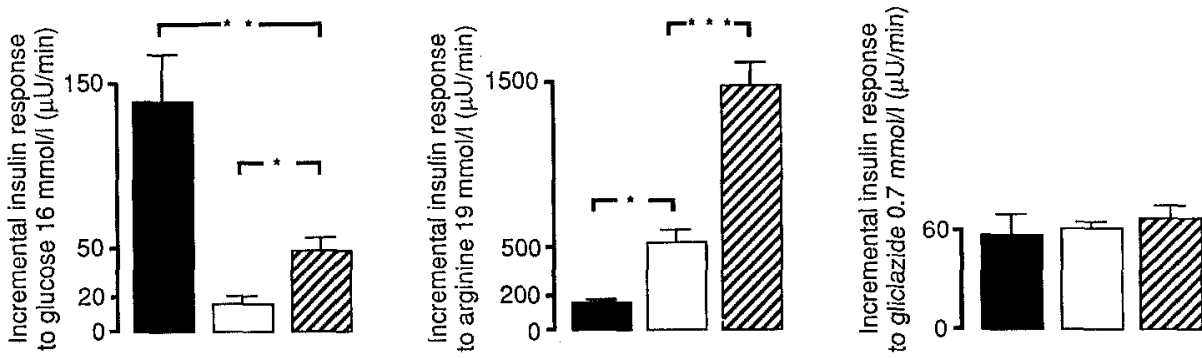

Fig.4. Incremental insulin response to $16 \mathrm{mmol} / 1$ glucose, $19 \mathrm{mmol} / 1$ arginine and $0.7 \mathrm{mmol} / 1$ gliclazide above basal release in untreated n0-STZ diabetic rats ( $\square$ ), n0-STZ diabetic rats that received a 30-day gliclazide therapy $(\mathbb{Q})$ and non-diabetic control rats $(\boldsymbol{\square})$. Values are mean \pm SEM of $6-9$ observations in each group. ${ }^{*} p<0.05,{ }^{* *} p<0.01$, $* * * p<0.001$

response in the untreated diabetic rats did elicit a first phase insulin release (Fig.1). However, the incremental insulin response to glucose compared to that in the untreated diabetic rats was only increased twofold (the difference did not reach statistical significance) in group A rats while it was increased fivefold $(p<0.05)$ in group B rats (Fig. 2). Nevertheless, the total insulin release in group B remained decreased fivefold compared to that in non-diabetic rats. After the glucose reduction in the perfusate (from 16 to $0 \mathrm{mmol} / \mathrm{l}$ ) there was a sluggish increase of insulin output by the pancreas of the treated (group A and group B) and the untreated n5-STZ rats (Fig. 1). This paradoxical pattern of response sharply contrasted with the rapid suppression of insulin release obtained after glucose reduction in the pancreas of nondiabetic rats (Fig. 3). In the absence of glucose, the insulin response to $19 \mathrm{mmol} / 1$ arginine was increased fourfold in the untreated n5-STZ rats compared to the nondiabetic rats. In the group A rats the total insulin response to arginine was not significantly modified as compared to untreated diabetic rats (despite an increased first phase secretory response) (Fig. 2). In the group B rats, it was twofold increased and the difference reached significance $(p<0.05)$ compared to release in the related untreated diabetic rats (Fig.2). The insulin responses to acute stimulation by $0.7 \mathrm{mmol} / 1$ gliclazide in group $\mathrm{A}$ and group $\mathrm{B}$ rats were similar to the corresponding response in non-diabetic rats (data not shown).

Insulin release in the $n 0-S T Z$ rats. Basal rates of insulin secretion were similar in untreated n0-STZ rats $(28 \pm 6 \mu \mathrm{U} / \mathrm{min})$ and treated $\mathrm{n} 0-\mathrm{STZ}$ rats $(61 \pm$ $12 \mu \mathrm{U} / \mathrm{min}$ ) but they were significantly enhanced $(p<0.01)$ in treated $\mathrm{n} 0-\mathrm{STZ}$ rats compared to control rats $(18 \pm 1 \mu \mathrm{U} / \mathrm{min})$ (Fig.3). Exposure of 30-day gliclazide treated n0-STZ pancreases to $16 \mathrm{mmol} / 1$ glucose significantly increased $(p<0.05)$ their insulin release threefold compared to the untreated n0-STZ rats, with the most prominent effect being on the first phase (Figs. 3 and 4). Nevertheless, it remained significantly decreased $(p<0.01)$ compared to control rats (Fig. 3 and 4). In pilot experiments we have evaluated the insulin release induced by $22 \mathrm{mmol} / \mathrm{l}$ glucose in n0-STZ rats. The incremental insulin response was significantly increased as compared to that of untreated n0-STZ pancreas (respectively $75 \pm 14 \mu \mathrm{U} / \mathrm{min}, n=6$ and $8 \pm$ $2 \mu \mathrm{U} / \min n=8, p<0.01)$ and compared to that of gliclazide treated n0-STZ pancreas stimulated with $16 \mathrm{mmol} / 1$ glucose (respectively $75 \pm 14 \mu \mathrm{U} / \mathrm{min} n=6$ and $49 \pm 7 \mu \mathrm{U} / \min n=8$ ) but remained significantly decreased compared to the response in non-diabetic rats $(288 \pm 54 \mu \mathrm{U} / \mathrm{min}, n=6, p<0.001)$. After the glucose reduction in the perfusate from 16 to $0 \mathrm{mmol} / 1$ there was a paradoxical increase of insulin output by the pancreas of the treated n0-STZ diabetic rats (Fig.3). The $19 \mathrm{mmol} / 1$ arginine-induced insulin release was increased in the untreated n0-STZ rats compared to the controls. It was increased threefold in the treated n0STZ rats compared to untreated n0-STZ rats $(p<0.001)$ (Fig. 3 and 4). The insulin response to acute stimulation by $0.7 \mathrm{mmol} / 1$ gliclazide remained unchanged in untreated n0-STZ rats compared to that in non-diabetic rats. Chronic gliclazide treatment did not significantly modify their insulin response to acute gliclazide stimulation (Fig. 3 and 4).

In other experiments (data not shown) we have estimated the insulin secretion in n0-STZ diabetic rats after acute (1 day) gliclazide treatment. The basal insulin release of 1-day treated n0-STZ rats was not significantly different from that measured in the non-diabetic rats. Exposure of the pancreases of these diabetic rats to $16 \mathrm{mmol} / 1$ glucose did not elicit any significant increase in the insulin output, thus indicating clearly that the Bcell response to glucose in these diabetic rats remained abnormal after the 1-day treatment. $19 \mathrm{mmol} / 1$ arginine induced a stimulation of insulin release that was significantly higher than that obtained in the non-diabetic rats, thus indicating that the acute gliclazide treatment was unable to modify the n0-STZ B-cell hypersensitivity to arginine. In response to a $0.7 \mathrm{mmol} / 1$ gliclazide challenge, the insulin release in the 1-day treated n0-STZ rats increased to a value similar to that of non-diabetic rats.

\section{Discussion}

Most of the data available in experimental animals treated long-term with sulfonylureas and related to their insulin response under these conditions has been 
obtained in normal non-diabetic rodents [26-29]. In the present paper the effect of chronic sulfonylurea administration was studied in rats with Type 2 diabetes induced by neonatal streptozotocin (n-STZ models) which appear more appropriate models as far as the abnormality of their B-cell function resembles to some extent that in the human disease $[17,23,30$, 31].

The data obtained in severely hyperglycaemic n5-STZ rats (group A) showed that the gliclazide treatment did not lower the plasma glucose concentrations, did not affect the pancreatic insulin stores, nor did it significantly modify the insulin release in vitro in response to glucose or arginine (in fact, a slight tendency to enhancement of both responses was detectable but did not reach statistical significance). Thus, in severely hyperglycaemic rats (non-fasting plasma glucose levels $>16 \mathrm{mmol} / 1$ ) long-term gliclazide treatment exerts no beneficial action toward the B-cell function and plasma glucose level. Such a conclusion is in line with previous observations obtained in other diabetic rat models [32, 33] whose shared characteristic was the severity of the basal hyperglycaemia ( $\geq 16 \mathrm{mmol} / \mathrm{l})$.

The results obtained in the less severely hyperglycaemic n5-STZ rats (group B) are quite strikingly different. In these pre-treated animals with non-fasting plasma glucose levels below $16 \mathrm{mmol} / \mathrm{l}$, the plasma glucose levels declined progressively reaching $8 \mathrm{mmol} / \mathrm{l}$ as a mean at the end of the treatment. Group B rats were thus considered to be gliclazide responders in contrast to group A rats. It is important to mention that no overlap between the 2 groups was noticed. In gliclazide treated group B n5-STZ rats the pancreatic insulin stores were increased compared to values in the n5-STZ group not treated with gliclazide; however, the difference did not reach significance and the pancreatic insulin stores in the gliclazide treated group B rats remained depleted by $76 \%$ compared to normal insulin stores. Although the mechanism for this increase is unknown, it may reflect the progressive reduction of hyperglycaemia during the gliclazide treatment. This is supported by the observations that islets of normal rats made hyperglycaemic for a long period show markedly degranulated $B$ cells and a low insulin content $[34,35]$ such a pattern being rapidly reversible with the return to normoglycaemia [35]. It has also been postulated that hyperglycaemia in vivo has a long-term effect of suppressing insulin synthesis [36]. However, regulation of insulin content remains poorly understood, being a balance of synthesis, release and intracellular degradation and one has to remain cautious in the further interpretation of the data in group B n5-STZ rats. In the gliclazide treated n5-STZ rats belonging to group $B$, the insulin release as tested in vitro was significantly improved as compared to untreated $\mathrm{n} 5-\mathrm{STZ}$ rats: responses to nutrient (glucose) and non-nutrient (arginine) secretagogues were both increased, while the response by the same pancreas to acute gliclazide stimulation remained normal (data not shown). The fact that the insulin response to gliclazide did not increase in the group B rats argues against the raised level of stored pancreatic insulin in these rats having any significant influence on insulin secretion. It has been proposed that chronic exposure of $\mathrm{B}$ cells to abnormally high glucose levels may be an important pathogenic factor in causing $\mathrm{B}$ cell dysfunction [35]. The relief of the hyperglycaemia during gliclazide treatment in group B rats could, therefore, account for the improvement of their secretory response. We believe, however, that this last assumption is not valid as the arginine-induced insulin release in the group B rats is in fact increased instead of being decreased (in this case the lowering of the basal plasma glucose level entirely explains the changes of B-cell function, due to the well-known modulating influence of glucose on the arginine-induced insulin secretion [17.j]).

Also, the findings with the n0-STZ rats showed that chronic gliclazide treatment improved the in vitro insulin secretion in response to glucose and arginine, and that the response is similarly enhanced with both secretagogues (threefold). In contrast, the insulin response to acute gliclazide remained normal. This was obtained in the absence of any significant change of the pancreatic insulin stores, or of the basal plasma glucose levels in the gliclazide treated $\mathrm{n} 0-\mathrm{STZ}$ rats, thus suggesting that the improvement of B-cell function detected here was not determined by pancreatic insulin content and/or hyperglycaemia. This is an interesting aspect of the study as the interpretation of the n0-STZ data reinforces that of data obtained with the group B n5-STZ rats.

It has been recently reported in humans with Type 2 diabetes that sustained exposure to sulfonylurea induces a selective unresponsiveness of the B cells to short-term sulfonylurea stimulation [37]. Such a desensitization to gliclazide was not detected in the n-STZ models at least over the 30-day treatment period.

A paradoxical insulin release occurred in both n0STZ and n5-STZ diabetic rats (treated or untreated) after a reduction from 16 to $0 \mathrm{mmol} / 1$ glucose. One possible mechanism stems from recent observations on the effect of glucose on B cell intracellular calcium. It has been postulated [38] that in some pathological situations (alloxan diabetic rats, human diabetes) calcium uptake into organelles predominates over intracellular influx so that cytoplasmic calcium falls; under these circumstances an acute lowering of glucose might mobilize these calcium stocks and cause an insulin response.

The possible site(s) in the B cell of the n-STZ rats which are positively modulated by chronic gliclazide treatment (and not acute treatment) are presently unknown. It is known that gliclazide half-life in vivo is be- 
tween 2-4 h [39] as estimated in normal or diabetic rats. Thus, one can consider that the concentration of gliclazide still remaining in the blood $24 \mathrm{~h}$ after gliclazide administration is close to zero. Furthermore, the possibility of an accumulation of gliclazide in the blood and/or tissue, following long-term administration in rats, is probably very low since it has been reported that the excretion of gliclazide was not significantly modified in rats receiving long-term administration of the drug (7 days) compared to rats receiving short-term treatment (1 day) [40].

Although one has to be cautious in relating findings obtained in diabetic animal models to diabetic patients, our results in the n0-STZ and n5-STZ (group B) rats agree with clinical reports which conclude that chronic sulfonylurea therapy augments both basal and stimulated first phase insulin secretion in Type 2 diabetes by increasing islet sensitivity to glucose $[15,16,41]$ while the acute sulfonylurea administration does not significantly improve their first phase insulin secretion [42].

Acknowledgements. We are grateful to Drs. E.Forgue-Lafitte and G. Rosselin (INSERM-Unite 55, Paris) for the supply of iodinated insulin and to INSERM (CRE 87.4013) and Laboratories Servier for financial support. P.Serradas is a recipient of a doctoral fellowship from the JNICT (Portugal).

\section{References}

1. Gotfredsen CF (1976) Dynamics of sulfonylurea-induced insulin release from the isolated perfused rat pancreas. Diabetologia 12: 339-342

2. Widstrom A, Cerasi E (1973) On the action of tulbutamide in normal man. Acta Endocrinol 72: 519-531

3. Pfeifer MA, Halter JB, Graf R, Porte D Jr (1980) Potentation of insulin secretion to nonglucose stimuli in normal man by tolbutamide. Diabetes $29: 335-340$

4. Pfeifer MA, Halter JB, Beard JB, Porte D Jr (1981) Differential effects of tolbutamide on first and second phase insulin secretion in noninsulin-dependent diabetes mellitus. J Clin Endocrinol Metab 53: $1256-1262$

5. Seltzer HS, Allen EW, Brennan MT (1965) Failure of prolonged sulfonylurea administration to enhance insulinogenic response to glycemic stimulus. Diabetes 14: 392-395

6. Reaven G, Dray J (1967) Effect of chlorpropamide on serum glucose and insulin concentrations in patients with maturity onset diabetes. Diabetes 16: 487-492

7. Feldman JM, Lebovitz HE (1971) Endocrine and metabolic effects of glibenclamide. Evidence for an extra pancreatic mechanism of action. Diabetes 20: 745-755

8. Duckworth WC, Solomon SS, Kitabchi CJ (1972) Effect of chronic sulfonylurea therapy on plasma insulin and proinsulin levels. J Clin Endocrinol Metab 35: 585-591

9. Gerich JE, Forsham PH, Kane JP, Karam JH (1977) The effect of chronic oral antidiabetic therapy on insulin and glucagon response to meal. Diabetes $26: 314-321$

10. Tun MH, Graham CA, Bradley RF, Gleason RE, Soeldner JS (1977) The effect of long-term therapy with oral hypoglycemic agents on the oral glucose tolerance test dynamics in male chemical diabetes. Diabetes $26: 561-570$

11. Holman RR, Turner RC (1978) Basal normoglycaemia attained with chlorpropamide in mild diabetes. Metabolism 27: $539-547$
12. Podolsky S, Burney SW (1979) Effect of long-term sulfonylurea therapy on plasma insulin and fasting lipid levels. Diabete Metab 5: $113-117$

13. Sönksen PH, Lowy C, Perkins JR, West TET (1981) Hormonal and metabolic effects of chlorpropamide, glibenclamide and placebo in a cross-over study in diabetics not controlled by diet alone. Diabetologia 20: 22-30

14. Barnes AJ, Crowley MF, Garbien KJT, Bloom A (1974) Effect of short and long-term chlorpropamide treatment on insulin release and blood glucose. Lancet I: 69-72

15. Judzewitsch RG, Pfeifer MA, Best JD, Beard JC, Halter JB, Porte D Jr (1982) Chronic chlorpropamide therapy of noninsulindependent diabetes augments basal stimulated insulin secretion by increasing islet sensitivity to glucose. J Clin Endocrinol Metab 55: $321-327$

16. Hosker JP, Burnett MA, Davies EG, Harries EA, Turner RC (1985) Sulfonylurea therapy doubles B-cell response to glucose in Type 2 diabetic patients. Diabetologia 28: 809-814

17. Giroix MH, Portha B, Kergoat M, Bailbé D, Picon L (1983) Glucose insensitivity and amino-acid hypersensitivity of insulin release in rats with non-insulin-dependent diabetes: a study with the perfused pancreas. Diabetes 32: 445-451

18. Robertson RP, Porte D (1973) The glucose receptor: a defective mechanism in diabetes mellitus distinct from the beta adrenergic receptor. J Clin Invest 52:870-876

19. Palmer JP, Benson JW, Walter RM, Ensinck JW (1976) Arginine stimulated acute phase of insulin and glucagon secretion in diabetic subjects. J Clin Invest 58: 565-570

20. Nesher R, Della Casa L, Litvin Y, Sinai J, Del Rio G, Bella Pevsner, Wax Y, Cerasi E (1987) Insulin deficiency and insulin resistance in Type 2 (non-insulin-dependent) diabetes: quantitative contributions of pancreatic and peripheral responses to glucose homeostasis. Eur J Clin Invest 17: 266-274

21. Ganda OP, Srikanta S, Brink SJ, Morris MA, Gleason RE, Soeldner JS, Eisenbarth GS (1984) Differential sensitivity to $\beta$-cell secretagogues in "early", Type 1 diabetes mellitus. Diabetes 33: $516-521$

22. Naidoo C, Jialal I, Suleman A, Rajput NC, Joubert SM (1986) Acute insulin response to glucagon, tolbutamide, and glucose in non-insulin-dependent diabetes of the young. Diabetes Care 9: $57-60$

23. Blondel O, Portha B (1989) Relationship between insulin deficiency and impairment of insulin action in vivo: a comparative study using different rat models of non-insulin-dependent diabetes induced by neonatal streptozotocin. Diabetes (to appear)

24. Kergoat M, Portha B (1985) In vivo hepatic and peripheral insulin sensitivity in rats with non-insulin-dependent diabetes induced by streptozotocin. Diabetes 34: 574-579

25. Freychet P, Roth J, Neville DM (1971) Monoiodoinsulin: demonstration of biological activity and binding to fat cells and liver membranes. Biochenn Biophys Res Commun 43: 400-408

26. Dunbar JC, Foà PP (1974) An inhibitory effect of tolbutamide and glibenclamide (Glyburide) on the pancreatic islets of normal animals. Diabetologia 10: 27-35

27. Schatz H, Steinle D, Pfeiffer EF (1977) Long-term actions of sulfonylureas on (Pro-)insulin biosynthesis and secretion. Horm Metab Res 9: 457-465

28. Filipponi P, Marcelli M, Nicoletti I, Pacifici R, Santeusanio F, Brunetti P (1983) Suppresive effect of long term sulfonylurea treatment on $A, B$, and D cells of normal rat pancreas. Endocrinology 113: 1972-1979

29. Sodoyez JC, Sodoyez-Goffaux F, Koch M, Rosu-Jerome F, de Vos CJ (1988) Metabolic effects of a 3-week treatment of obese zucker rats with gliclazide. Diabetologia 31: 446 (Abstract)

30. Portha B, Picon L, Rosselin G (1979) Chemical diabetes in the adult rat as the spontaneous evolution of neonatal diabetes. Diabetologia 17: $371-377$

31. Weir GC, Leahy JL, Bonner-Weir S (1986) Experimental reduction of B-cell mass: implications for the pathogenesis of diabetes. Diab Metab Rev 2: 125-161 
32. Murphy ED, Anderson JW (1974) Tissue glycolytic and gluconeogenic enzyme activities in mild and moderately diabetic rats: influence of tolbutamide administration. Endocrinology 94: 27-34

33. Clark A, Bown E, King T, Vanhegan RI, Turner RC (1982) Islet changes induced by hyperglycaemia in rats. Effect of insulin or chlorpropamide therapy. Diabetes 31: 319-325

34. Logothetopoulos J, Davidson JK, Haist RE, Best CH (1965) Degranulation of beta cells and loss of pancreatic insulin after infusions of insulin antibody or glucose. Diabetes 14: 439-500

35. Leahy JL, Cooper HE, Deal DA, Weir GC (1986) Chronic hyperglycaemia is associated with impaired glucose influence on insulin secretion: a study in normal rats using chronic in vivo glucose infusions. J Clin Invest 77: 908-915

36. Orland MJR, Chyn R, Permutt MA (1985) Modulation of proinsulin messenger RNA after partial pancreatectomies in rats: relationship to glucose homeostasis. J Clin Invest 75: 2047-2055

37. Karam JH, Sanz N, Salamon E, Nolt S (1986) Selective unresponsiveness of pancreatic $\beta$-cells to acute sulfonylurea stimulation during sulfonylurea theapy in NIDDM. Diabetes $35: 1314-1320$

38. Hellman B, Hällgreen $H$, Abrahamsson $H$, Bergsten $P$, Berne $C$, Gylfe E, Rorsman P, Wide L (1985) The dual action of glucose on the cystolic $\mathrm{Ca}^{2+}$ activity in pancreatic B cells. Demonstration of an inhibitory effect of glucose on insulin release in the mouse and man. Biomed Biochim Acta 44: 63-70

39. Benakis A, Vitus J, Glasson B (1974) Métabolisme et pharmaconinétique du gliclazide ${ }^{14} \mathrm{C}$ chez le rat rendu diabétique ex- périmentalement par la streptozotocine. J Pharmacol (Paris) 5: 299-308

40. Miyazaki H, Fujii T, Yoshida K, Arakawa S, Furukawa H, Suzuki H, Kagemoto A, Hashimoto M, Tamaki N (1983) Disposition and metabolism of ${ }^{3} \mathrm{H}$ ) gliclazide in rats. Eur $J$ Drug Metab Pharmacokinet 8: 117-131

41. Couturier $E$ (1986) Gliclazide on long-term therapy increases insulin response to glucose of Type 2 diabetes. Diab Res Clin Pract 1: 343-347

42. Groop L, Luzi L, Melander A, Groop PH, Ratheiser K, Simonson DC, DeFronzo RA (1987) Different effects of glyburide and glipizide on insulin secretion and hepatic glucose production in normal and NIDDM subjects. Diabetes 36:1320-1328

Received: 16 December 1988

and in revised form: 17 May 1989

Dr. Bernard Portha

Laboratoire Physiologie du Developement

Université Paris 7

Tour 33-43, 1er étage

2 Place Jussieu

F-75251 Paris Cedex 05

France 